\title{
AN IMPROVED METHOD OF DETECTING QUASSIA AND CERTAIN OTHER HOP-SUBSTITUTES IN BEER.
}

Br Alfred H. Allen.

Read at the Meeting, May, 1887.

Hitherto, the detection of hop-substitutes in beer has had for English analysts little more than an academic interest. There has been no definition of beer, nor standard of strength or quality, and hence the brewer has been free to employ any hop-substitute that could fairly be regarded as non-injurious. Now, however, that there are two Bills before Parliament, both of which aim at rendering the employment of hop-substitutes illegal, unless duly acknowledged, the question has acquired considerable practical importance. If the Bills in question ever become law, it will devolve on the public analyst to certify to the presence or absence of hop-substitutes, but, as was recently pointed out by the Chancellor of the Exchequer to a deputation which waited on him, it would be of no use to pass an Act forbidding the unacknowledged use of hopsubstitutes, unless it was possible to detect infringements of the law. Hence it has become important for public analysts to see how far the more important hop-substitutes can be definitely detected in beer, or at any rate distinguished from hops.

The problem in quéstion is by no means a simple one. Beer itself is a highly complex and variable product, and some of the normal constituents add to the difficulty of detecting hop-substitutes. The problem is further complicated by the possible presence of several substitutes simultaneously, together with actual hops. Then the bitter principles, to which the hop-substitutes owe their employment, have in some cases been very imperfectly studied, and belong to a class of bodies by no means distinguished for strong chemical affinities or for characteristic reactions. In fact, the most general and striking property of the majority of hop-substitutes is the intensity of their bitter taste, a character which materially increases the difficulty of detecting them owing to the very moderate amount employed to give the beer the desired flavour. There is one other complication of practical importance, and that is the very considerable quantity of beer usually recommended to be used for the analysis. Thus if two litres be used for the main examination, as is recommended by Dragendorff, at least twice that quantity should be submitted to the analyst, and hence twelve litres would have to be purchased. The necessity of purchasing so large a quantity as two and a half gallons of each beer would almost certainly render the Act abortive.

In looking into the question, therefore, I have aimed at reducing the amount of beer employed as low as possible.

In the last number of the ANALYST I gave a list of references to articles in English periodicals, etc. connected with detection of hop-substitutes in beer. These I have carefully studied, and they have formed the foundation of the following statements and proposals.

Dragendorff, who has published a very elaborate method for the recognition of a large number of possible hop-substitutes (Jour. Chem. Soc. xxvii, 818 ; xlii, 103), operates on two litres of beer, precipitates the concentrated liquid with basic acetate of lead, further concentrates the filtrate and adds a large volume (1000 to 1200 c.c.) of absolute alcohol! The spirit is subsequently driven off, and the various principles extracted by a systematic employment of immiscible solvents. 
Wittstein (Jour. Chem. Soc. xxix, 767) operates in a similar manner, but works on one litre, and omits the treatment with acetate of lead, as indeed did Dragendorff in his older method. In the method described by me in my "Commercial Organic Analysis" (vol. i., page 97), based on a process of Enders, one litre of beer is employed, the concentrated liquid treated with alcohol, the filtrate precipitated with ether, and the filtered liquid evaporated, the residue redissolved in alcohol, treated with water, and the solution precipitated with acetate of lead.

Several of the writers on the subject state that on precipitating a beer with basic acetate of lead the hop-bitter is wholly precipitated, and hence, if the concentrated filtrate still have a bitter taste, the presence of some hop-substitute is certain.* This difference seemed to me so important that I have very carefully investigated it, and find it perfectly in accordance with the fact. I prefer, however, to employ neutral acetate of lead instead of the basic or ammoniacal acetate, as the latter reagents are liable to precipitate certain bitter principles not removed by the first. On the other hand, the hop-bitter is very perfectly precipitated by neutral lead acetate, and this statement is equally true of an infusion of hops purposely prepared and of a beer in which hops is the sole bitter used; but I have some reason to think that basic acetate of lead is liable to effect a less perfect separation of the hop-bitter.

In attempting to improve these processes, I have endeavoured to dispense with the use of alcohol, and yet separate the bitter principles from the sugar and other bodies which disguise the bitter taste and interfere with application of chemical tests, and find that a very satisfactory product for further treatment can be obtained by the following simple method.

One litre of the beer is evaporated to about 300 c.c., and is then precipitated while hot with a solution of neutral acetate of lead. The precipitate is filtered off, the filtrate allowed to become cool, and any further precipitate is also removed. The excess of lead is then removed from the filtrate by sulphuretted hydrogen, and the liquid filtered and further concentrated to about 150 c.c. I prefer sulphuretted hydrogen to sulphuric acid or a sulphate, as the lead sulphide seems to carry down a notable quantity of colouring matter.

The treatment with lead acetate removes all tannin, phosphates, etc., and the hop-resin and lupulin are also completely precipitated, while all or nearly all hop-substitutes remain in solution.

The next object is to separate the sugar, dextrin, and mineral constituents of the beer as perfectly as possible from the active principles of the various hop-substitutes. Instead of precipitating the carbo-hydrates, etc., by excess of strong alcohol, I prefer to remove the bitters from the aqueous liquid itself by agitation with suitable immiscible solvents.

The object being to extract as many active principles as possible in the simplest possible way, leaving their mutual separation and recognition for further consideration,

* This distinction between the bitter principles of hops and hop-substitutes is referred to in the work entitled "Chemistry applied to the Arts and Manufactures," edited by Chas. Vincent, and often described as the "New Edition of Muspratt's Chemistry." The process is also described in Wynter Blyth's work on the "Analysis of Food", and forms an essential part of Enders' method of detecting bitter substances, so that there is a very general consensus of opinion as to the value of the test. 
I employ chloroform, as having the most general solvent action. It separates with tolerable ease from the aqueous liquid, and should be employed as long as it leaves a notably bitter residue on evaporation. In many of my experiments I relied on the traces of lactic and other acids naturally present in beer to produce the requisite degree of acidity, but I am now of opinion that the addition of a little dilute sulphuric acid is advantageous, if not actually necessary, in some cases. The extraction with chloroform being complete, ether should next be used, the treatment being repeated as long as any notably bitter principle is extracted. Finally, the aqueous liquid is rendered alkaline with ammonia, and agitated with chloroform or ether-chloroform, to extract any alkaloids.

The following arrangement shows the behaviour of the more important bitter principles when the aqueous liquid is agitated in succession with chloroform, ether, and ammonia and ether-chloroform. I have personally verified the behaviour of the substances to the names of which asterisks are attached.

1. Extracted by chloroform from acid solutions :-

Absinthin (wormwood).

*Anthemin (chamomiles).

Colchicine (colchicum), imperfectly.

*Colocynthin (colocynth, or bitter apple), imperfectly.

*Calumbin, and probably some berberine (calumba), bright yellow, and highly fluorescent.

*Gentipicrin (gentian), very imperfectly.

*Picric acid (artificial), yellow, imperfectly.

Picrotoxin (cocculus indicus), with difficulty.

*Quassiin (quassia wood).

2. Subsequently extracted by ether from acid solutions :-

*Chiratin (chiretta).

*Colocynthin (colocynth, or bitter apple).

*Gentipicrin (gentian).

*Picric acid, yellow.

*Picrotoxin (cocculus indicus).

3. Subsequently extracted by ether-chloroform from alkaline solutions :-

* Berberine (calumba root).

Colchicine (colchicum).

By evaporating off the solvent, warming the residue with a little alcohol, and then adding water, solutions are obtained, which will be bitter if any of the above substances be present. A very small quantity of the substance is required for this test ; indeed the use of too large an amount must be carefully avoided, or the sense of taste will be found to be wholly paralysed, for the remainder of the day at any rate.

It will be seen that chloroform or ether extracts from acidulated aqueous liquids almost the whole of the above bitters. The subsequent treatment with ether-chloroform in alkaline solution is usually unnecessary, as the principles of calumba and colchicum are in part extracted by acid chloroform. Seeing that the bitter principles of hops are entirely precipitated by neutral acetate of lead, the presence of some hop-substitute is absolutely certain if the chloroform or ether residue has a marked bitter taste. This can be ascertained in the course of a few hours, by the simple method above indicated, and half a pint of the beer is amply sufficient for the purpose. 
The presence of a hop-substitute being proved by the marked bitter taste of the chloroform or ether extract, it will of course be very desirable to ascertain its nature, and in some important cases this can, fortunately, be effected very satisfactorily. In others we may expect future investigation to afford the necessary assistance.

I have made special endeavours to ascertain the possibility of definitely recognising quassia, which is one of the most important of the hop-substitutes actually employed. For this purpose I prepared quassiin in a moderately pure state by exhausting quassia wood with hot water, and treating the decoction with acetate of lead and chloroform, in the manner recommended for beer. The quassiin was obtained with some difficulty in a distinctly crystalline state, and otherwise it presented a close general resemblance to the description of it given by other observers. The following characters and tests were specially verified.

Quassiin is intensely and persistently bitter, sparingly soluble in cold water, more readily in hot, and easily soluble in alcohol. Its best solvent is chloroform, which extracts it readily from acidulated solutions.

An aqueous solution of quassiin does not reduce Fehling's solution, or ammonionitrate of silver. The solid substance gives no coloration (or merely yellow) when treated with strong sulphuric acid, or with nitric acid of $1.25 \mathrm{sp}$. gr. ; nor is any colour produced on warming. These four negative reactions are important; for picrotoxin reduces Fehling's solution, and gives an orange-red colour with sulphuric acid; gentipicrin and menyanthin reduce ammonio-nitrate of silver, and the former gives a red colour, and the latter a yellowish-brown, changing to violet-red when warmed with sulphuric acid; and other bitters mostly give more or less characteristic reactions.

A solution of quassiin gives a white precipitate with tannin. The reaction is used by Christensen, Oliveri, and others to isolate quassiin from its solutions, and by Enders to separate it from picrotoxin. In my hands the reaction has not proved satisfactory. The liquid is very difficult to filter, and the filtrate still retains an intensely bitter taste, showing that the precipitation is very incomplete. As an analytical method the reaction is useless, but it is of some value as a qualitative test.* The test must be made in a cold solution.

Quassiin gives a brown coloration with ferric chloride. The reaction is best observed by moistening a quassiin residue in porcelain with a few drops of a weak alcoholic solution of ferric chloride, and applying a gentle heat. A fine mahogany-brown coloration is produced.

The most delicate and characteristic test for quassiin is based on an observation of Christensen. On treating quassiin with bromine a derivative is obtained, which is stated to be more bitter than the original substance. On adding caustic soda the bitter taste is said to be destroyed, but a product of a fine yellow colour is obtained. I am unable to confirm the destruction of the bitter taste, at least entirely, but the coloration is marked and characteristic.

The following is the best way of applying the test. The substance to be tested for quassiin is dissolved in a little chloroform, or if a liquid is agitated with chloroform,

* Possibly more complete precipitation of quassiin by tannin could be effected in an alcoholic solution. 
and the aqueous layer separated. The chloroformic solution is then treated with bromine water until the yellow colour remains after agitation, showing that the bromine has been used in slight excess. The aqueous liquid is then removed (or if small in volume may be neglected), and the chloroform agitated with ammonia. This produces immediate destruction of the colour due to the bromine, and if quassiin be absent both the chloroform and ammoniacal liquid will be colourless. In presence of quassiin the ammonia will be coloured a bright yellow.

The chloroform-residues from camomiles, calumba, colocynth, cocculus, and chiretta do not give any similar reactions with bromine and ammonia. The ether-residue from chiretta gives a straw-yellow coloration gradually changing to a dull purplish-brown, but the fact that no such reaction is yielded by the chloroform solution of the drug renders confusion with quassia impossible. Picric acid yields a solution in chloroform which is but slightly coloured compared with the deep yellow liquid produced on subsequent agitation with ammonia ; but if its presence be suspected it can be readily and completely removed by agitating the chloroformic solution with soda or ammonia, and separating the alkaline liquid before employing bromine.

With a view of ascertaining how far the foregoing reactions of quassiin were likely to be of service in practice, I added to one litre of a mild beer, which had been previously proved to yield no bitter principle to chloroform after treatment with acetate of lead, sufficient infusion of quassia to make a perceptible difference in the flavour. The liquid was concentrated, precipitated with neutral lead acetate, the filtrate treated with sulphuretted hydrogen, and the refiltered liquid further concentrated and agitated with chloroform. On evaporating the chloroform a residue was obtained which had an intensely bitter taste, and yielded a solution which gave a white precipitate with tannin, but did not reduce ammonio-nitrate of silver. The residue gave no colour on warming with concentrated sulphuric acid, but gave a well-developed mahogany-brown colour with ferric chloride. By the bromine and ammonia test it gave a strong yellow coloration.

The amount of residue obtained would have sufficed to obtain all these reactions several times, so that it may be considered established that quassia can be detected with certainty and facility in a moderate quantity of beer containing it.

The employment of chiretta as a hop-substitute has been repeatedly recorded by previous observers, but no tests are given for it by Dragendorff or others who have worked on the subject. I found it in quantity in two hop-substitutes I recently examined, and suspect its presence in a third. The active principle (chiratin, $\mathrm{C}_{25} \mathrm{H}_{48} \mathrm{O}_{15}$ ) is intensely bitter, sparingly soluble in cold water, rather more so in hot, and is readily dissolved by alcohol and ether, the latter solvent readily removing it from its aqueous solution. On the other hand, chloroform removes but little bitter principle from an aqueous infusion of chiretta. Chiratin is a neutral substance, decomposed by dilute acids into ophelic acid and chiratogenin. It does not reduce Fehling's solution, gives a copious precipitate with tannin, and is not precipitated by neutral lead acetate. The reaction of the etherresidue from infusion of chiretta with bromine and ammonia has already been described.

It is evident that our knowledge of the chemistry of the vegetable bitters available as hop-substitutes is very incomplete, and it is only by its further study we can hope to fully solve the problem of their detection in beer. But I believe we can already 
distinguish with certainty and facility between "hops" and "not hops," and that ought to suffice in many cases. When we examine butter we are content to define the admixture as "foreign fat," and we make no attempt to specify the exact nature or origin of the foreign fat employed. I submit that we are fully able to take a similar position with respect to hops and hop-substitutes. 